\title{
EFEKTIVITAS PEMANFAATAN BIOGAS UNTUK MENUNJANG KETAHANAN ENERGI (Studi Di Desa Pendoworejo Kecamatan Girimulyo Kabupaten Kulon Progo Daerah Istimewa Yogyakarta)
}

\author{
Dyah Sri Palupi \\ Kantor Kementerian Agama Kabupaten Bantul \\ lupi_810o@yahoo.com
}

\begin{abstract}
The development of renewable energy was one of the crises of energy solutions. The purposes of the research were to analyzed the effectiveness of biogas utilization and examine the connection of that utilization with energy resilience at Pendoworejo.

The research method was qualitative descriptive analysis approach. Total amount the biodigesters were 183 units. Purposive sampling technique was used to determined the samples. The total informants were 55 people. Data collection techniques included literature studies, observation, interviews, and documents studies.

The research results were $30.26 \%$ able to used and $69.77 \%$ unable to used. The continuity of effectiveness in utilizations was for daily using in the category low (25.58\%), sometimes in using in the category very low (4.65\%) and damage in the category enough (69.77\%). The biogas utilization or function effectiveness were for cooking in the category high (86.82\%), for the generator set (3.1\%) and others (10.08\%) in the category very low. The effectiveness for providing the needs were providing all needs in the category very low (9.3\%), part of the needs in the category low (20.93\%) and not at all in the category enough (69.77\%). The effectiveness of biogas utilization at Pendoworejo village for energy resilience were at low level. The expectation in the next the Pendoworejo village would be self-supporting in energy, but the energy resources of biogas at the village had not reached more than $60 \%$ of total required energy. The effectiveness of biogas utilization at Pendoworejo village currently were not being able to supported the energy resilience yet.
\end{abstract}

Keywords: Effectiveness, Biogas, Energy Resilience.

\begin{abstract}
ABSTRAK
Pengembangan energi terbaharukan merupakan salah satu solusi krisis energi. Penelitian bertujuan untuk menganalisis tingkat efektivitas pemanfaatan biogas dan mengkaji hubungan efektivitas pemanfaatan biogas di Desa Pendoworejo dengan ketahanan energi.

Metode penelitian yaitu kualitatif dengan pendekatan analisis deskriptif. Jumlah biodigester 183 unit. Penentuan sampel dengan teknik purposive sampling. Jumlah informan 55 orang. Teknik pengumpulan data meliputi studi kepustakaan, observasi, wawancara, dan studi dokumentasi.

Hasil penelitian yaitu 30,26\% biodigester berfungsi dan 69,77\% dalam kondisi rusak. Efektivitas kontinuitas pemanfaatan dan ketersediaan biogas yakni pemanfaatan harian dalam kategori rendah (25,58\%), pemanfaatan kadang-kadang dalam kategori sangat rendah (4,65\%) dan kondisi rusak dalam kategori cukup (69,77\%). Efektivitas pemanfaatan atau fungsi yakni untuk memasak dalam kategori tinggi (86,82\%), genset (3,1\%) dan lainnya $(10,08 \%)$ dalam kategori sangat rendah. Efektivitas pemenuhan kebutuhan energi berbahan biogas yaitu memenuhi kebutuhan
\end{abstract}


Dyah Sri Palupi -- Efektivitas Pemanfaatan Biogas Untuk Menunjang Ketahanan Energi (Studi Di Desa Pendoworejo Kecamatan Girimulyo Kabupaten Kulon Progo Daerah Istimewa Yogyakarta)

dalam kategori sangat rendah (9,3\%), sebagian memenuhi kebutuhan dalam kategori rendah (20,93\%), dan tidak memenuhi kebutuhan dalam kategori cukup (69,77\%). Efektivitas pemanfaatan biogas di Desa Pendoworejo termasuk rendah. Desa Pendoworejo diharapkan menjadi Desa Mandiri Energi, namun sumber energi dari biogas belum mencapai lebih dari 60\%. Efektivitas pemanfaatan biogas di Desa Pendoworejo belum mampu menunjang ketahanan energi.

Kata kunci: Efektivitas, Biogas, Ketahanan Energi.

\section{PENGANTAR}

Setiap bangsa berusaha mendapatkan sumber energi dari dalam dan luar negeri (Dirwan, 2012). Energi fosil yang digunakan saat ini sekitar 80\% (Campbell, 1983). Energi fosil merupakan energi tidak terbaharukan. Indonesia menjadi anggota Organization for Petroleum Exporting Countries (OPEC) tahun 1962-2009. Indonesia kini menjadi importir neto (Nugroho, 2005). Pengimpor bahan bakar menunjukkan ketahanan energi Indonesia rendah (Dirwan, 2012).

Ketahanan energi merupakan kemampuan suatu negara sehingga tersedia pasokan energi yang handal, terjangkau, efisien, ramah lingkungan, dan diterima konsumen akhir (Indrawan dan Wijaya, 2011). Sumber energi tidak terbaharukan terkuras dan peningkatan kebutuhan energi menimbulkan ancaman krisis energi. Daya tahan energi Indonesia berkurang dan krisis energi mengancam. Salah satu pemecahan krisis energi yakni pengembangan energi terbaharukan.

Pemerintah mengupayakan program Desa Mandiri Energi (DME). Energi merupakan titik masuk pengembangan kegiatan ekonomi perdesaan (Prasetyo dan Hanifah, 2011). Sumber daya pertanian dan peternakan Indonesia cukup besar. Sumber daya untuk pangan dan berpotensi sebagai sumber energi dengan cara pemanfaatan kotoran ternak menjadi biogas. Nilai kalor biogas yaitu 4.800-6.700 kkal/m³ (Nurhasanah dkk., 2006). Biogas dihasilkan bakteri melalui fermentasi bahan organik dalam kondisi tanpa oksigen (Elizabeth dan Rusdiana, 2011).

Desa Pendoworejo telah mengembangkan energi alternatif biodigester sebagai penghasil biogas. Terkait dengan potensi pemanfaatan limbah peternakan untuk bahan biogas maka penelitian dengan judul "Efektivitas Pemanfaatan Biogas untuk Menunjang Ketahanan Energi (Studi Di Desa Pendoworejo Kecamatan Girimulyo Kabupaten Kulon Progo Daerah Istimewa Yogyakarta)” sangat strategis dan memberikan informasi dalam strategi pengembangan energi alternatif berbasis sumber daya lokal.

Penelitian ini memiliki beberapa tujuan yaitu: Pertama, menganalisis efektivitas pemanfaatan biogas di Desa Pendoworejo. Kedua, mengkaji hubungan efektivitas pemanfaatan biogas di Desa Pendoworejo dengan ketahanan energi.

Metode penelitian yang digunakan yakni kualitatif dengan pendekatan analisis deskriptif. Studi kepustakaan dilakukan di Yogyakarta. Penelitian lapangan dilaksanakan di Desa Pendoworejo dan instansi terkait di Wates dan Pengasih pada tanggal 1 Desember 2014 hingga 27 Februari 2015. Populasi berjumlah 183 orang sesuai dengan jumlah peternak yang mempunyai biodigester. Sampel ditentukan dengan teknik non probability sampling secara khusus yaitu purposive sampling.

Sampel yakni informan yang mengetahui pemanfaatan biogas dan memiliki biodigester. 
Jumlah informan 55 orang yakni peternak, pengurus kelompok tani atau gabungan kelompok tani (gapoktan), tokoh masyarakat (tomas), penyuluh, kepala desa, kepala dukuh, dan instansi terkait. Informan peternak yaitu 43 orang yaitu peternak murni dan peternak yang berperan ganda sebagai pengurus kelompok tani, pengurus gapoktan, tokoh masyarakat, kepala dukuh atau kepala desa.

Teknik pengumpulan data yang digunakan yakni: (1) Studi kepustakaan; (2) Observasi non partisipan; (3) Wawancara perseorangan (in depth interview) dan kelompok (Focus Group Discussion); (4) Studi dokumentasi dari Kantor Lingkungan Hidup, Dinas Kelautan Perikanan dan Peternakan, Dinas Perindustrian Perdagangan dan Energi Sumber Daya Mineral, dan Kantor Ketahanan Pangan dan Penyuluhan Pertanian Perikanan Kehutanan, dan pencatatan Desa Pendoworejo.
Data dianalisis dengan teknik persentase. Rumus efektivitas yaitu: $\frac{\text { Hasil nyata }}{\text { Sasaran }}$ 100\% (PIMLPPM, 1997). Interpretasi nilai berdasarkan tabel yang disusun oleh Arikunto (1998). Tabel interpretasi nilai dapat dilihat dalam tabel 1.

Tabel 1. Interpretasi nilai (\%)

\begin{tabular}{cc}
\hline Besar nilai efektivitas (\%) & Nilai interpretasi efektivitas \\
\hline $80-100$ & Tinggi \\
$60-79,9$ & Cukup \\
$40-59,9$ & Agak rendah \\
$20-39,9$ & Rendah \\
$0-19,9$ & Sangat rendah \\
\hline
\end{tabular}

Sumber: Arikunto, 1998.

Data dicek dan ricek dengan triangulasi. Triangulasi metode yakni membandingkan beberapa metode yang digunakan yaitu studi kepustakaan, observasi, wawancara, dan studi dokumentasi. Triangulasi sumber berupa perbandingan data yang berasal dari peternak,

Tabel 2. Jumlah instalasi biogas di Kabupaten Kulon Progo 2008-2014 (unit)

\begin{tabular}{|c|c|c|c|c|c|c|c|c|c|c|c|c|c|c|c|}
\hline \multirow{2}{*}{ No } & \multirow{2}{*}{ Instansi } & \multicolumn{7}{|c|}{ Pembangunan instalasi biogas } & \multicolumn{7}{|c|}{ Total instalasi biogas per tahun } \\
\hline & & 2008 & 2009 & 2010 & 2011 & 2012 & 2013 & 2014 & 2008 & 2009 & 2010 & 2011 & 2012 & 2013 & 2014 \\
\hline 1. & $\begin{array}{l}\text { Kantor } \\
\text { Lingkungan } \\
\text { Hidup (kab) }\end{array}$ & 28 & 48 & 44 & 21 & 26 & 30 & 11 & 28 & 76 & 120 & 141 & 167 & 197 & 208 \\
\hline 2. & $\begin{array}{l}\text { Kementerian } \\
\text { Lingkungan } \\
\text { Hidup (pusat) } \\
\end{array}$ & - & - & 167 & - & - & - & - & - & - & 167 & 167 & 167 & 167 & 167 \\
\hline 3. & $\begin{array}{l}\text { Diskepenak } \\
\text { (kab) }\end{array}$ & $87 *)$ & 5 & 9 & - & - & - & - & 87 & 92 & 101 & 101 & 101 & 101 & 101 \\
\hline 4. & $\begin{array}{l}\text { Dinas } \\
\text { Perindustrian } \\
\text { Perdagangan dan } \\
\text { ESDM (kab) }\end{array}$ & - & - & - & - & 30 & 23 & 64 & - & - & - & - & 30 & 53 & 117 \\
\hline 5. & $\begin{array}{l}\text { Dinas Pekerjaan } \\
\text { Umum dan } \\
\text { ESDM (provinsi) }\end{array}$ & - & $1 * *)$ & - & - & - & 5 & - & - & 1 & 1 & 1 & 6 & 6 & 6 \\
\hline 6. & $\begin{array}{l}\text { Kementerian } \\
\text { ESDM (pusat) }\end{array}$ & - & - & - & - & 17 & 37 & - & - & - & - & - & 17 & 54 & 54 \\
\hline 7. & $\begin{array}{l}\text { Instansi provinsi } \\
* *)\end{array}$ & - & - & 4 & - & - & - & - & - & - & 4 & 4 & 4 & 4 & 4 \\
\hline & Jumlah & 115 & 54 & 224 & 21 & 73 & 95 & 75 & 115 & 169 & 393 & 414 & 487 & 582 & 657 \\
\hline
\end{tabular}

Keterangan: kab=kabupaten; *) Total unit instalasi biogas tahun 2004-2008;

**) Hasil wawancara dengan peternak, 2014.

Sumber: Dinas Kelautan Perikanan dan Peternakan, 2014; Dinas Perindustrian Perdagangan dan ESDM 2014; Kantor Lingkungan Hidup, 2014; wawancara dengan peternak, 2014. 
kelompok tani, gabungan kelompok tani, desa, dan instansi terkait.

\section{PEMBAHASAN}

\section{Instalasi Biogas di Desa Pendoworejo}

Kantor Lingkungan Hidup, Dinas Kelautan Perikanan dan Peternakan (Diskepenak), dan Dinas Perindustrian Perdagangan dan Energi Sumber Daya Mineral (ESDM) membangun instalasi biogas di Kabupaten Kulon Progo. Selain itu instansi pusat dan provinsi juga terlibat. Jumlah instalasi biogas di Kabupaten Kulon Progo 2008-2014 (unit) dapat dilihat dalam tabel 2.

Jumlah instalasi biogas terbanyak pada tahun 2014 dalam tabel 2 bersumber dari Kantor Lingkungan Hidup kabupaten (208 unit). Jumlah instalasi biogas pada tahun 2013 sebanyak 582 unit, sedangkan Idhiar Nugroho dari Dinas Perindustrian Perdagangan dan ESDM menyatakan 752 unit. Instalasi biogas sebanyak 170 unit tidak diketahui sumbernya. Peneliti kesulitan mendapat jumlah dan sumber instalasi biogas dengan tepat. Instansi hanya memiliki data jumlah biodigester yang dibangun dan tembusan dari instansi pusat atau provinsi. Perubahan staf yang menangani bantuan biodigester menyebabkan informasi yang diperoleh terbatas. Informasi lain diperoleh saat wawancara dengan peternak.

Bantuan biodigester di Desa Pendoworejo dikelompokkan menjadi tiga yaitu dari
Kementerian Lingkungan Hidup, Diskepenak, dan instansi lain. Sumber bantuan biodigester, jumlah informan peternak, dan persentase di Desa Pendoworejo dapat dilihat dalam tabel 3.

Jumlah bantuan biodigester di Desa Pendoworejo di dalam tabel 3 meningkat dari tahun 2004-2010. Biodigester terbanyak bantuan dari Kementerian Lingkungan Hidup (167 unit). Total bantuan biodigester sampai dengan tahun 2010 sebanyak 183 unit. Jumlah informan peternak yaitu 43 orang $(23,5 \%)$.

\section{Penilaian Efektivitas Pemanfaatan Biogas di Desa Pendoworejo}

Biogas dikatakan efektif jika biodigester berfungsi baik, demikian juga sebaliknya. PernyataantersebuthasilFoccus GroupDiscussion (FGD). Kriteria efektivitas pemanfaatan biogas di Desa Pendoworejo dilihat dari tiga sudut pandang yaitu kontinuitas ketersediaan dan pemanfaatan biogas, pemanfaatan atau fungsi biogas, dan pemenuhan kebutuhan energi berbahan biogas.

\section{Efektivitas Dilihat dari Kontinuitas Ketersediaan dan Pemanfaatan Biogas}

Efektivitas pertama dilihat dari kontinuitas ketersediaan dan pemanfaatan biogas. Kriteria yang digunakan yakni harian, kadang-kadang dan kondisi rusak. Kontinuitas ketersediaan dan pemanfaatan biogas terdapat dalam tabel 4.

Tabel 3. Sumber bantuan biodigester, jumlah informan peternak, dan persentase di Desa Pendoworejo

\begin{tabular}{|c|c|c|c|c|c|c|c|c|c|c|c|}
\hline \multirow[t]{2}{*}{ No } & \multirow{2}{*}{$\begin{array}{l}\text { Sumber bantuan } \\
\text { biodigester }\end{array}$} & \multicolumn{4}{|c|}{ Pembangunan biodigester } & \multicolumn{4}{|c|}{ Total biodigester per tahun } & \multirow{2}{*}{$\begin{array}{l}\text { Jumlah informan } \\
\text { peternak }\end{array}$} & \multirow{2}{*}{$\begin{array}{l}\text { Persentase } \\
\text { (\%) }\end{array}$} \\
\hline & & 2004 & 2008 & 2009 & 2010 & 2004 & 2008 & 2009 & 2010 & & \\
\hline 1 & $\begin{array}{l}\text { Kementerian } \\
\text { Lingkungan Hidup }\end{array}$ & - & - & - & 167 & - & - & - & 167 & 34 & 20,36 \\
\hline 2 & Diskepenak & 2 & 1 & 3 & 4 & 2 & 3 & 6 & 10 & 5 & 50 \\
\hline 3 & Instansi lain & - & - & 1 & 5 & - & - & 1 & 6 & 4 & 66,67 \\
\hline & Total & 2 & 1 & 4 & 176 & 2 & 3 & 7 & 183 & 43 & 23,5 \\
\hline
\end{tabular}

Sumber: Pencatatan Desa Pendoworejo, 2014; Analisis data primer, 2015. 
Jurnal Ketahanan Nasional, Vol. 21, No. 2, Agustus 2015: 78-88

Tabel 4. Kontinuitas ketersediaan dan pemanfaatan biogas

\begin{tabular}{|c|c|c|c|c|c|c|c|c|c|}
\hline \multirow[b]{2}{*}{ No } & \multirow{2}{*}{$\begin{array}{c}\text { Sumber } \\
\text { bantuan } \\
\text { biodigester }\end{array}$} & \multicolumn{3}{|c|}{ Kontinuitas (orang) } & \multirow[b]{2}{*}{ Total } & \multicolumn{3}{|c|}{ Persentase (\%) } & \multirow[b]{2}{*}{ Total } \\
\hline & & Harian & Kadang-kadang & Rusak & & Harian & Kadang-kadang & Rusak & \\
\hline 1 & $\begin{array}{l}\text { Kementerian } \\
\text { Lingkungan Hidup }\end{array}$ & 6 & 1 & 27 & 34 & 17,65 & 2,94 & 79,41 & 100 \\
\hline 2 & Diskepenak & 3 & 1 & 1 & 5 & 60 & 20 & 20 & 100 \\
\hline 3 & Instansi lain & 2 & - & 2 & 4 & 50 & - & 50 & 100 \\
\hline & Total & 11 & 2 & 30 & 43 & 25,58 & 4,65 & 69,77 & 100 \\
\hline
\end{tabular}

Sumber: Analisis data primer, 2015.

Nilai interpretasi efektivitas didasarkan pada tabel dari Arikunto (1998). Kontinuitas ketersediaan dan pemanfaatan biogas bersumber dari bantuan Kementerian Lingkungan Hidup yakni pemanfaatan harian dalam kategori sangat rendah $(17,65 \%)$, kadang-kadang dalam kategori sangat rendah (2,94\%), dan kondisi rusak dalam kategori cukup (79,41\%). Kontinuitas ketersediaan dan pemanfaatan biogas bersumber dari Diskepenak yaitu pemanfaatan harian tergolong cukup (60\%), kadang-kadang tergolong rendah (20\%) dan kondisi rusak tergolong rendah (20\%). Kontinuitas ketersediaan dan pemanfaatan biogas bantuan dari instansi lain yaitu pemanfaatan harian termasuk agak rendah (50\%) dan kondisi rusak termasuk agak rendah (50\%).

Total kontinuitas ketersediaan dan pemanfaatan biogas baik harian dan kadangkadang dalam kategori rendah (30,26\%). Jika ketiga instansi dibandingkan maka kontinuitas ketersediaan dan pemanfaatan biogas harian yang tertinggi yaitu bersumber dari Diskepenak, instansi lain dan Kementerian Lingkungan Hidup. Kontinuitas ketersediaan dan pemanfaatan biogas kadang-kadang yaitu bersumber dari Diskepenak selanjutnya instansi lain. Kontinuitas ketersediaan dan pemanfaatan biogas dipengaruhi beberapa faktor yaitu kapasitas, konstruksi biodigester, pengisian, kondisi bak dan saluran pembuangan.
Kapasitas biodigester bantuan dari Kementerian Lingkungan Hidup yakni 4,5 $\mathrm{m}^{3}$, Diskepenak yaitu $9 \mathrm{~m}^{3}$, dan instansi lain antara $6 \mathrm{~m}^{3}-12 \mathrm{~m}^{3}$. Kubah biodigester bantuan dari Kementerian Lingkungan Hidup bocor di sambungan. Para peserta FGD menyatakan bahwa campuran biodigester bantuan dari Kementerian Lingkungan Hidup kurang memenuhi standar. Perbandingan semen:pasir yang baik yaitu 1:3. Hal ini sesuai dengan pendapat Elizabeth dan Rusdiana (2011) yang menyatakan bahwa kapasitas dan konstruksi biodigester menentukan kuantitas produksi biogas. Digester harus anaerob. Apabila digester bocor maka volumebiogas tertampung berkurang dan api yang dihasilkan kecil.

Pengisian biodigester yang baik dilakukan setiap hari, namun peternak di Desa Pendoworejo mengisi 2-3 hari sekali. Pengisian tergantung kesibukan, saat panen pengisian biodigester seminggu sekali. Jika biodigester tidak diisi akan macet. Faktor yang lain yang berpengaruh yaitu kondisi bak penuh sehingga produksi biogas berkurang. Saluran pembuangan yang tidak memadai juga membuat kontinuitas ketersediaan dan pemanfaatan biogas tidak sesuai harapan.

\section{Efektivitas Dilihat dari Pemanfaatan atau Fungsi Biogas}

Efektivitas kedua dilihat dari pemanfaatan atau fungsi biogas. Kriteria yang dipakai 
yaitu untuk memasak, genset dan lainnya. Pemanfaatan lainnya yakni hasil samping berupa limbah biogas yang digunakan untuk pupuk tanaman. Pemanfaatan atau fungsi biogas dapat dilihat dalam tabel 5 .

Biodigester bersumber dari bantuan Kementerian Lingkungan Hidup untuk memasak dalam kategori tinggi (91\%), sedangkan lainnya dalam kategori sangat rendah (9\%). Biodigester bantuan Diskepenak untuk memasak tergolong tinggi (80\%), sedangkan lainnya tergolong rendah (20\%). Biodigester bantuan dari instansi lain untuk memasak termasuk agak rendah (58,33\%), genset termasuk rendah (33,3\%), sedangkan lainnya termasuk sangat rendah (8,33\%).

Total pemanfaatan biogas yaitu untuk memasak dalam kategori tinggi (86,82\%). Pemanfaatan genset $(3,1 \%)$ dan lainnya (10,08\%) dalam kategori sangat rendah. Jika tiga instansi dibandingkan maka biodigester yang dimanfaatkan untuk memasak terbanyak yakni bersumber dari bantuan Kementerian
Lingkungan Hidup, kemudian bantuan Diskepenak dan instansi lain. Genset hanya dimanfaatkan oleh informan yang mendapat bantuan dari instansi lain. Pemanfaaatan lainnya yang terbanyak yakni bersumber dari bantuan Diskepenak, Kementerian Lingkungan Hidup, kemudian instansi lain.

Pemanfaatan biogas tergantung komponen bantuan yang diberikan. Komponen bantuan dari Kementerian Lingkungan Hidup dan Diskepenak yaitu untuk memasak. Biodigester bantuan dari instansi lain untuk memasak dan genset. Biodigester Muh. Paino berasal dari bantuan Diskepenak untuk memasak dengan kapasitas $9 \mathrm{~m}^{3}$. Biodigester tersebut pernah dipakai Lembaga Ilmu Pengetahuan Indonesia (LIPI) Gunung Kidul untuk genset dan berfungsi. Genset dibawa sendiri oleh LIPI.

\section{Efektivitas Dilihat dari Pemenuhan Kebutuhan Energi Berbahan Biogas}

Efektivitas ketiga dilihat dari pemenuhan kebutuhan energi berbahan biogas. Kriteria

Tabel 5. Pemanfaatan atau fungsi biogas

\begin{tabular}{|c|c|c|c|c|c|c|c|c|c|}
\hline \multirow{2}{*}{ No } & \multirow{2}{*}{$\begin{array}{c}\text { Sumber bantuan } \\
\text { biodigester }\end{array}$} & \multicolumn{3}{|c|}{ Pemanfaatan atau fungsi (orang) } & \multirow{2}{*}{ Total } & \multicolumn{3}{|c|}{ Persentase (\%) } & \multirow{2}{*}{ Total } \\
\hline & & Memasak & Genset & Lainnya & & Memasak & Genset & Lainnya & \\
\hline 1 & $\begin{array}{l}\text { Kementerian Lingkungan } \\
\text { Hidup }\end{array}$ & 31 & - & 3 & 34 & 91 & - & 9 & 100 \\
\hline 2 & Diskepenak & 4 & - & 1 & 5 & 80 & - & 20 & 100 \\
\hline \multirow[t]{2}{*}{3} & Instansi lain & 2,33 & 1,33 & 0,33 & 4 & 58,33 & 33,33 & 8,33 & 100 \\
\hline & Total & 37,33 & 1,33 & 4,33 & 43 & 86,82 & 3,1 & 10,08 & 100 \\
\hline
\end{tabular}

Sumber: Analisis data primer, 2015.

Tabel 6. Pemenuhan kebutuhan energi berbahan biogas

\begin{tabular}{|c|c|c|c|c|c|c|c|c|c|}
\hline \multirow[b]{2}{*}{ No } & \multirow{2}{*}{$\begin{array}{c}\text { Sumber } \\
\text { bantuan biodigester }\end{array}$} & \multicolumn{3}{|c|}{ Pemenuhan kebutuhan (orang) } & \multirow[b]{2}{*}{ Total } & \multicolumn{3}{|c|}{ Persentase (\%) } & \multirow[b]{2}{*}{ Total } \\
\hline & & Memenuhi & Sebagian & $\begin{array}{c}\text { Tidak } \\
\text { memenuhi }\end{array}$ & & Memenuhi & Sebagian & $\begin{array}{c}\text { Tidak } \\
\text { memenuhi }\end{array}$ & \\
\hline 1 & $\begin{array}{l}\text { Kementerian } \\
\text { Lingkungan Hidup }\end{array}$ & - & 7 & 27 & 34 & - & 20,59 & 79,41 & 100 \\
\hline 2 & Diskepenak & 2 & 2 & 1 & 5 & 40 & 40 & 20 & 100 \\
\hline 3 & Instansi lain & 2 & - & 2 & 4 & 50 & - & 50 & 100 \\
\hline & Total & 4 & 9 & 30 & 43 & 9,3 & 20,93 & 69,77 & 100 \\
\hline
\end{tabular}

Sumber: Analisis data primer, 2015. 
pemenuhan kebutuhan energi berbahan biogas yaitu memenuhi, sebagian atau tidak memenuhi. Pemenuhan kebutuhan energi berbahan biogas dapat terdapat tabel 6 .

Pemenuhan kebutuhan energi berbahan biogas bersumber dari bantuan Kementerian Lingkungan Hidup yaitu sebagian memenuhi kebutuhan dalam kategori rendah (20,59\%) dan tidak memenuhi kebutuhan dalam kategori cukup (79,41\%). Biodigester bantuan dari Diskepenak yaitu memenuhi kebutuhan termasuk agak rendah (40\%), sebagian memenuhi kebutuhan termasuk agak rendah (40\%), dan tidak memenuhi kebutuhan termasuk rendah (20\%). Biodigester bantuan dari instansi lain yaitu memenuhi kebutuhan (50\%) dan tidak memenuhi kebutuhan (50\%) termasuk agak rendah.

Total pemenuhan kebutuhan energi berbahan biogas yaitu memenuhi kebutuhan dalam kategori sangat rendah (9,3\%), sebagian memenuhi kebutuhan dalam kategori rendah (20,93\%), dan tidak memenuhi kebutuhan dalam kategori cukup $(69,77 \%)$. Jika tiga instansi dibandingkan dalam pemenuhan kebutuhan energi berbahan biogas maka kriteria memenuhi kebutuhan yang tertinggi yaitu bantuan dari instansi lain, kemudian dari Diskepenak. Kriteria memenuhi sebagian kebutuhan yaitu bantuan dari Diskepenak, selanjutnya dari Kementerian Lingkungan Hidup. Kriteria tidak memenuhi kebutuhan yang tertinggi yaitu dari bantuan Kementerian Lingkungan Hidup, instansi lain dan Diskepenak.

Salah seorang informan bernama Tugiyanto menerangkan bahwa jumlah produksi biogas tiga ekor sapi lebih banyak dibandingkan satu ekor. Muh. Paino, Tugiran, Rajiyo, dan Supadi mengemukakan bahwa kebutuhan biogas untuk harian terpenuhi.
Biodigester keempat informan tersebut berasal dari bantuan Diskepenak dan instansi lain dengan kapasitas $6 \mathrm{~m}^{3}$ dan $9 \mathrm{~m}^{3}$. Biodigester Sutopo berasal dari Kementerian Lingkungan Hidup dengan kapasitas 4,5 m³. Biogas Sutopo hanya memenuhi sebagian kebutuhan.

Biodigester bantuan Kementerian Lingkungan Hidup hanya sebagian memenuhi kebutuhan. Pemenuhan kebutuhan energi berbahan biogas bantuan dari Diskepenak dan instansi lain lebih baik jika dibandingkan bantuan dari Kementerian Lingkungan Hidup. Biodigester bantuan dari Kementerian Lingkungan Hidup bocor di sambungan. Kapasitas dan konstruksi biodigester mempengaruhi volume gas yang ditampung. Jika volume gas sedikit maka biogas tidak mampu memenuhi kebutuhan.

\section{Kendala-kendala dalam Pemanfaatan Biogas di Desa Pendoworejo}

Pemanfaatan biogas oleh masyarakat di Desa Pendoworejo tidak terlepas dari berbagai kendala. Kendala-kendala dalam pemanfaatan biogas di Desa Pendoworejo secara rinci dapat dilihat dalam tabel 7.

Kendala-kendala pemanfaatan biogas dalam tabel 7 yakni aspek bahan baku, teknis, lingkungan, sosial ekonomi, manajemen dan keberlanjutan. Aspek teknis, sosial ekonomi, dan keberlanjutan merupakan kendala-kendala yang utama. Berdasarkan aspek bahan baku maka kendala yang paling dominan yaitu jumlah sapi menurun. Bak, tutup biodigester, atau peralon bocor, dan kompor atau genset rusak merupakan kendala utama dari aspek teknis. Aspek lingkungan yang paling dominan berupa protes pencemaran limbah. Kendala utama dari aspek sosial ekonomi yakni malas mengisi biodigester, pemeliharaan yang rumit dan 
Dyah Sri Palupi -- Efektivitas Pemanfaatan Biogas Untuk Menunjang Ketahanan Energi (Studi Di Desa Pendoworejo Kecamatan Girimulyo Kabupaten Kulon Progo Daerah Istimewa Yogyakarta)

Tabel 7. Kendala-kendala dalam pemanfaatan biogas di Desa Pendoworejo

\begin{tabular}{|c|c|c|c|c|c|c|}
\hline & \multicolumn{6}{|c|}{ Aspek } \\
\hline & Bahan baku & Teknis & Lingkungan & Sosial ekonomi & Manajemen & Keberlanjutan \\
\hline  & $\begin{array}{l}\text { 1. Sapi mati atau } \\
\text { dijual } \\
\text { 2. Sapi diganti } \\
\text { domba } \\
\text { 3. Jumlah sapi } \\
\text { menurun } \\
\text { 4. Jumlah } \\
\text { kandang } \\
\text { kelompok } \\
\text { masih sedikit }\end{array}$ & $\begin{array}{l}\text { 1. Bak, tutup } \\
\text { biodigester, atau } \\
\text { peralon bocor } \\
\text { 2. Ketersediaan air } \\
\text { kurang } \\
\text { 3. Kompor atau } \\
\text { genset rusak } \\
\text { 4. Plastik } \\
\text { penampung gas } \\
\text { bocor } \\
\text { 5. Bak pencampur } \\
\text { sejajar lantai } \\
\text { kandang } \\
\text { 6. Bak } \\
\text { pembuangan } \\
\text { penuh } \\
\text { 7. Tidak ada } \\
\text { saluran limbah } \\
\text { 8. Kesalahan } \\
\text { konstruksi }\end{array}$ & $\begin{array}{l}\text { 1. Protes } \\
\text { pencemaran } \\
\text { limbah } \\
\text { 2. Kesulitan akses } \\
\text { sumber air } \\
\text { 3. Tanah bergerak } \\
\text { 4. Konstruksi bak } \\
\text { pencerna dekat } \\
\text { mata air } \\
\text { 5. Kondisi tanah } \\
\text { miring } \\
\text { 6. Keamanan } \\
\text { dan pencurian } \\
\text { ternak }\end{array}$ & $\begin{array}{l}\text { 1. Malas mengisi } \\
\text { biodigester } \\
\text { 2. Pemeliharaan } \\
\text { yang rumit } \\
\text { dan kesibukan } \\
\text { peternak } \\
\text { 3. Perpindahan } \\
\text { domisili } \\
\text { 4. Kekurangan } \\
\text { dana } \\
\text { 5. Hambatan } \\
\text { perbaikan sarana } \\
\text { prasarana } \\
\text { 6. Pengisian } \\
\text { biodigester } \\
\text { terlalu cepat dan } \\
\text { banyak } \\
\text { 7. Pecampuran } \\
\text { bahan kurang } \\
\text { homogen }\end{array}$ & $\begin{array}{l}\text { 1. Belum ada } \\
\text { tim pengelola } \\
\text { biogas } \\
\text { 2. Koordinasi } \\
\text { antar instansi } \\
\text { terkait kurang } \\
\text { optimal } \\
\text { 3. Koordinasi } \\
\text { antar } \\
\text { peternak, } \\
\text { kelompok } \\
\text { tani, } \\
\text { gapoktan, } \\
\text { penyuluh, } \\
\text { tomas, dan } \\
\text { pemerintah } \\
\text { belum optimal }\end{array}$ & $\begin{array}{l}\text { 1. Belum ada } \\
\text { yang membuat } \\
\text { biodigester } \\
\text { mandiri } \\
\text { 2. Jumlah } \\
\text { biodigester } \\
\text { yang berfungsi } \\
\text { menurun } \\
\text { 3. Keluhan biogas } \\
\text { macet } \\
\text { 4. Limbah } \\
\text { biogas belum } \\
\text { dikembangkan } \\
\text { 5. Belum bermitra } \\
\text { dengan Badan } \\
\text { Usaha Milik } \\
\text { Negara atau } \\
\text { perusahaan } \\
\text { swasta }\end{array}$ \\
\hline
\end{tabular}

Sumber: Analisis data primer, 2015.

kesibukan peternak, serta hambatan perbaikan sarana prasarana. Kendala dominan dari aspek manajemen yaitu belum ada tim pengelola biogas. Kendala utama dari aspek keberlanjutan yaitu limbah biogas belum dikembangkan dan belum bermitra dengan Badan Usaha Milik Negara atau perusahaan swasta.

\section{Strategi-strategi Prospektif dalam Mengatasi Kendala-kendala Pemanfaatan Biogas di Desa Pendoworejo}

Upaya mengatasi kendala-kendala dalam pemanfaatan biogas di Desa Pendoworejo sebagian telah dilakukan. Strategi-strategi prospektif dalam mengatasi kendala-kendala pemanfaatan biogas dapat dilihat dalam tabel 8.

Enam aspek dari strategi-strategi prospektif dalam tabel 8 yakni pemenuhan bahan baku, perbaikan teknis, pengendalian lingkungan, pengembangan sosial ekonomi, pengoptimalan manajemen dan pengembangan keberlanjutan. Strategi-strategi prospektif yang utama yakni perbaikan teknis, pengembangan sosial ekonomi, dan pengembangan keberlanjutan. Strategi prospektif dari aspek pemenuhan bahan baku yaitu kredit lunak untuk membeli sapi. Aspek perbaikan teknis dapat dilaksanakan dengan memperbaiki bak, tutup biodigester, atau pralon, membersihkan kompor atau genset rutin dan membuat kompor sederhana.

Strategi prospektif dari aspek pengendalian lingkungan yakni sosialisasi yang komprehensif pada tetangga sekitar. Aspek pengembangan sosial ekonomi dapat dilakukan dengan memotivasi supaya tidak malas dan bosan, gotong rotong anggota kelompok tani, dan membangun fasilitas pendukung perbaikan sarana prasarana. Strategi prospektif dari aspek pengoptimalan manajemen yaitu membentuk tim pengelola biogas. Aspek pengembangan keberlanjutan dapat dilaksanakan dengan mengembangkan 
Tabel 8. Strategi-strategi prospektif dalam mengatasi kendala-kendala pemanfaatan biogas di Desa Pendoworejo

\begin{tabular}{|c|c|c|c|c|c|c|}
\hline & \multicolumn{6}{|c|}{ Aspek } \\
\hline & $\begin{array}{l}\text { Pemenuhan bahan } \\
\text { baku }\end{array}$ & Perbaikan teknis & $\begin{array}{l}\text { Pengendalian } \\
\text { lingkungan }\end{array}$ & $\begin{array}{l}\text { Pengembangan } \\
\text { sosial ekonomi }\end{array}$ & $\begin{array}{l}\text { Pengoptimalan } \\
\text { manajemen }\end{array}$ & $\begin{array}{c}\text { Pengembangan } \\
\text { berkelanjutan }\end{array}$ \\
\hline 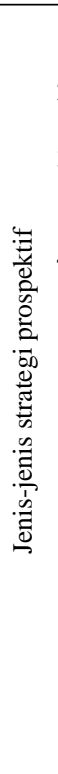 & $\begin{array}{l}\text { 1. Introduksi pola } \\
\text { gadhuh sapi } \\
\text { 2. Merendam } \\
\text { kotoran domba } \\
\text { 3. Kredit lunak } \\
\text { untuk membeli } \\
\text { sapi } \\
\text { 4. Mengem } \\
\text { bangkan kandang } \\
\text { kelompok }\end{array}$ & $\begin{array}{l}\text { 1. Memperbaiki bak, } \\
\text { tutup biodigester } \\
\text { atau pralon } \\
\text { 2. Penyediaan air } \\
\text { yang mencukupi } \\
\text { 3. Membersih } \\
\text { kan kompor, } \\
\text { genset rutin atau } \\
\text { membuat kompor } \\
\text { sederhana } \\
\text { 4. Mengganti plastik } \\
\text { dengan fiber } \\
\text { 5. Membuat bak } \\
\text { pencampur lebih } \\
\text { rendah dari lantai } \\
\text { kandang } \\
\text { 6. Menguras bak } \\
\text { penampungan } \\
\text { rutin } \\
\text { 7. Membuat saluran } \\
\text { limbah } \\
\text { 8. Memperbaiki } \\
\text { konstruksi }\end{array}$ & $\begin{array}{l}\text { 1. Sosialisasi yang } \\
\text { komprehensif } \\
\text { pada tetangga } \\
\text { sekitar } \\
\text { 2. Menyalurkan air } \\
\text { dari sumber } \\
\text { 3. Penggunaan } \\
\text { bahan tahan tanah } \\
\text { bergerak } \\
\text { 4. Menguras dekat } \\
\text { mata air } \\
\text { 5. Membuat } \\
\text { penyangga atau } \\
\text { menimbun } \\
\text { 6. Menjaga ternak } \\
\text { secara teratur }\end{array}$ & $\begin{array}{l}\text { 1. Memotivasi } \\
\text { supaya tidak } \\
\text { malas dan bosan } \\
\text { 2. Gotong rotong } \\
\text { anggota } \\
\text { kelompok tani } \\
\text { 3. Mengerahkan } \\
\text { pemuda } \\
\text { 4. Kredit lunak } \\
\text { untuk perbaikan } \\
\text { 5. Membangun } \\
\text { fasilitas } \\
\text { pendukung } \\
\text { perbaikan sarana } \\
\text { prasarana } \\
\text { 6. Mengisi } \\
\text { biodigester } \\
\text { secukupnya } \\
\text { 7. Mencampur } \\
\text { bahan hingga } \\
\text { homogen }\end{array}$ & $\begin{array}{l}\text { 1. Membentuk tim } \\
\text { pengelola biogas } \\
\text { 2. Meningkatkan } \\
\text { koordinasi antar } \\
\text { instansi } \\
\text { 3. Meningkatkan } \\
\text { koordinasi } \\
\text { antar peternak, } \\
\text { gapoktan, } \\
\text { kelompok tani, } \\
\text { penyuluh, tomas, } \\
\text { dan pemerintah }\end{array}$ & $\begin{array}{l}\text { 1. Memotivasi } \\
\text { pembangunan } \\
\text { biodigester } \\
\text { mandiri } \\
\text { 2. Mempertahankan } \\
\text { biodigester yang } \\
\text { berfungsi } \\
\text { 3. Sosialisasi biogas } \\
\text { tidak macet } \\
\text { 4. Mengembangkan } \\
\text { usaha baru dari } \\
\text { limbah biogas } \\
\text { 5. Bermitra dengan } \\
\text { Badan Usaha } \\
\text { Milik Negara } \\
\text { atau perusahaan } \\
\text { swasta }\end{array}$ \\
\hline
\end{tabular}

Sumber: Analisis data primer, 2015.

usaha baru dari limbah biogas dan bermitra dengan Badan Usaha Milik Negara atau perusahaan swasta.

\section{Efektivitas Pemanfaatan Biogas di Desa Pendoworejo}

Biodigester yang berfungsi yaitu sebanyak 30,26\% dan kondisi rusak sebanyak 69,77\%. Persentase efektivitas kontinuitas ketersediaan dan pemanfaatan biogas untuk pemanfaatan harian dalam kategori rendah (25,58\%), pemanfaatan kadang-kadang dalam kategori sangat rendah (4,65\%), dan kondisi rusak dalam kategori cukup (69,77\%). Persentase efektivitas pemanfaatan dan fungsi biogas untuk memasak termasuk tinggi (86,82\%), genset termasuk sangat rendah $(3,1 \%)$ dan lainnya termasuk sangat rendah (10,08\%). Persentase efektivitas yang memenuhi kebutuhan tergolong sangat rendah $(9,3 \%)$, sebagian tergolong rendah (20,93\%) dan tidak memenuhi tergolong cukup
(69,77\%). Efektivitas pemanfaatan biogas di Desa Pendoworejo termasuk dalam kriteria rendah.

\section{Hubungan Efektivitas Pemanfaatan Biogas Dengan Ketahanan Energi di Desa Pendoworejo}

Masyarakat Desa Pendoworejo menggunakan bahan bakar berupa kayu bakar, LPG dan biogas. Penggunaan bahan bakar berdasarkan informasi yang berasal dari informan peternak berbeda-beda yaitu: (1) kayu bakar, (2) LPG, (3) biogas, (4) kayu bakar dan LPG, (5) kayu bakar dan biogas, (6) LPG dan biogas, dan (7) kayu bakar, LPG, dan biogas. Kementerian Pembangunan Daerah Tertinggal (PDT) memberikan bantuan untuk pengembangan peternakan. Bantuan berupa dana bergulir dan empat unit biodigester diberikan di Desa Pendoworejo. Pemerintah Kabupaten Kulon Progo berharap bantuan 
biodigester akan mewujudkan DME di Desa Pendoworejo (Pemerintah Kabupaten Kulon Progo, 2010). Desa Mandiri Energi merupakan desa yang lebih dari $60 \%$ kebutuhan listrik dan bahan bakar dipenuhi dari sumber energi terbarukan (Kementerian Energi dan Sumber Daya Mineral, 2015).

Jumlah KK di Desa Pendoworejo per tanggal 31 Januari 2015 yaitu 1.951. Jumlah KK yang memiliki biodigester yaitu 183 (9,38 \%). Jika efektivitas pemanfaatan biogas dibandingkan dengan jumlah sumber energi terbaharukan maka masih jauh dari harapan. Jumlah sumber energi DME yaitu lebih dari 60\%, sedangkan jumlah biodigester termasuk rendah (9,38\%). Jumlah biodigester yang memenuhi kebutuhan dalam kategori sangat rendah $(9,3 \%)$ dan sebagian memenuhi kebutuhan dalam kategori rendah (20,93\%). Efektivitas pemanfaatan biogas di Desa Pendoworejo belum dapat menunjang ketahanan energi.

\section{SIMPULAN}

Berdasarkan hasil penelitian yang dilakukan di Desa Pendoworejo maka dapat diambil simpulan sebagai berikut:

Pertama, efektivitas pemanfaatan biogas di Desa Pendoworejo masih tergolong dalam kategori rendah. Biodigester yang berfungsi sebanyak $30,26 \%$ dan kondisi rusak sebanyak 69,77\%. Pemanfaatan biogas di Desa Pendoworejo dapat ditingkatkan dengan beberapa cara yakni: (1) Membentuk tim pengelola biogas; (2) Memotivasi masyarakat melalui penyuluhan dan pertemuan kelompok; (3) Gotong royong untuk memperbaiki biodigester; (4) Mengelola limbah biogas untuk pupuk padat dan cair; (5) Menyediakan kredit lunak untuk membeli sapi; (6) Membuat kompor sederhana; dan (7) Membangun biodigester yang berkualitas dan fasilitas pendukung perbaikan sarana dan prasarana.

Kedua, hubungan efektivitas pemanfaatan biogas di Desa Pendoworejo dengan ketahanan energi yaitu efektivitas pemanfaatan biogas belum mampu menunjang ketahanan energi. Jumlah KK di Desa Pendoworejo yaitu 1.951 dan jumlah KK yang memiliki biodigester yaitu 183 (9,38\%). Sumber energi terbaharukan dari biogas belum mencapai lebih dari $60 \%$. Harapan Desa Pendoworejo menjadi Desa Mandiri Energi belum dapat terwujud.

\section{DAFTAR PUSTAKA}

Arikunto, Suharsini. 1998. Prosedur Penelitian: Suatu Pendekatan Praktik. Jakarta: Bina Aksara.

Campbell, Ian. 1983. Biomass, Catalysts and Liquid Fuels. Great Britain: Holt Rinehart and Wiston Ltd.

Dirwan, A. 2012. "Peningkatan Ketahanan Pangan dan Energi sebagai Bagian dari Perwujudan Ketahanan Nasional”. Jurnal Mitra Manajemen. Vol. 4. No. 1.

Elizabeth, Roosganda dan S. Rusdiana. 2011. Efektivitas Pemanfaatan Biogas sebagai Sumber Bahan Bakar dalam Mengatasi Biaya Ekonomi Rumah Tangga di Pedesaan. Bogor: Pusat Sosial Ekonomi dan Kebijakan Pertanian.

Indrawan, Natarianto dan Muhammad Ery Wijaya. 2011. "Addressing Palm Biodiesel as Renewable Fuel for the Indonesian Power Generation Sector: Java-MaduraBali System”. The Journal for Technology and Science. Vol. 22. No. 4.

Nugroho, Hanan. 2005. Apakah Persoalannya pada Subsidi BBM? Tinjauan terhadap Masalah Subsidi BBM, Ketergantungan pada Minyak Bumi, Manajemen 
Energi Nasional, dan Pembangunan Infrastruktur Energi. Jakarta: Badan Perencanaan Nasional.

Nurhasanah, Ana, Teguh Wikan Widodo, Ahmad Asari, dan Elita Rahmarestia. 2006. Perkembangan Digester Biogas di Indonesia (Studi Kasus di Jawa Barat dan Jawa Tengah). Serpong: Balai Besar Pengembangan Mekanisasi Pertanian.

PIM-LPPM. 1997. Kamus Istilah Manajemen. Jakarta: PT. Pustaka Binaman Pressindo.

Prasetyo, Yanu Endar dan Umi Hanifah. 2011. “Pengorganisasian Masyarakat Desa Mandiri Energi: Studi Kasus PLTMH di Desa Palakka, Kecamatan Maiwa, Kabupaten Enrekang, Sulawesi Selatan”. Jurnal Komunitas. Volume 5. Nomor 1.

\section{Internet:}

Kementerian Energi dan Sumber Daya Mineral. 2015. Laporan Akuntabilitas Kinerja
Instansi Pemerintah (LAKIP) Direktorat Jenderal Energi Baru, Terbarukan dan Konservasi Energi Tahun 2013. <http:// ebtke.esdm.go.id/post/2014/07/16/637/ lakip.ditjen.ebtke.2013> (diakses 13 Maret 2015).

Pemerintah Kabupaten Kulon Progo. 2010. Kementerian PDT Tetap Kucurkan Bantuan untuk Kulon Progo. <http:// www.kulonprogokab.go.id/v21> (diakses 13 Maret 2015).

\section{Wawancara:}

1. Idhiar Nugroho, Dinas Perindustrian, Perdagangan dan ESDM

2. Muh. Paino: Tokoh Masyarakat/Peternak

3. Tugiyanto: Tokoh Masyarakat/Peternak

4. Tugiran: Tokoh Masyarakat/Peternak

5. Rajiyo: Tokoh Masyarakat/Peternak

6. Supadi: Tokoh Masyarakat/Peternak 